\section{Periodontal Effect of}

\section{Nonfunction in Monkeys}

by

BruCe L. Pihlstrom,* D.D.S., M.S.

SIGURD P. RAMF JORD, ** L.D.S.,PH.D.

AlTHOUGH THE PERIODONTAL EFFECTS of nonfunction have been studied extensively, the histologic and clinical significance of nonfunction remains unclear. Studies of humans ${ }^{1-14}$ and animals ${ }^{15-20}$ indicate that nonfunction leads to narrowing of the periodontal membrane and loss of functional orientation of the principle fibers. In humans $^{5,8,9,12,21}$ and monkeys ${ }^{20,22}$ an increase in thickness of cementum has been reported associated with nonfunction. The supporting bone of nonfunctional teeth in humans ${ }^{1,2,5,11,12,23}$ and rats ${ }^{17,24}$ exhibits increased size of marrow spaces and thin trabeculae. There is evidence of crestal apposition of bone adjacent to supra-erupted nonfunctional teeth both in humans ${ }^{13}$ and monkeys. ${ }^{20}$ Both crestal apposition ${ }^{25,} 26$ and resorption $^{15,17,24}$ have been reported with nonfunction in rodents. Increased calculus retention on nonfunctional teeth has been observed in humans. ${ }^{11}$ The periodontal status in animals varied from minimal inflammation, ${ }^{15,} 17$ pocket depth, ${ }^{17,} 20$ and recession, ${ }^{20,} 26$ to varying degrees of ulceration and inflammation, ${ }^{24}$ increased pocket depth, ${ }^{15}$ and recession. ${ }^{15}$ No difference in the degree of inflammation between functional and nonfunctional teeth was observed in monkeys. ${ }^{20}$

The lack of agreement concerning the relationship between degrees of gingival inflammation and nonfunction, and the unsolved significance of nonfunction in pocket formation, gingival recession, and loss or gain of bone at the alveolar crest, indicates a need for further studies under better controlled experimental conditions than the previously reported observations of rather subjective nature.

\section{Material and Experimental Methodology}

Five adult rhesus monkeys (four females and one male) with all teeth including third molars present were selected for the study. The animals all had some supra and subgingival calculus, and mild to moderately

University of Michigan School of Dentistry and the Veterans Administration Hospital, Ann Arbor, Michigan 48104.

*USAF Medical Center, Scott Air Force Base, Belleville, Illinois 62225 .

**Professor and Chairman, Department of Periodontics, University of Michigan School of Dentistry, Ann Arbor, Michigan 48104. severe gingivitis. The two oldest animals (according to amount of occlusal wear of the third molars) had incipient periodontitis with pockets generally $3-4 \mathrm{~mm}$ deep.

In order to equalize the experimental conditions as much as possible, the teeth of all monkeys were scaled and polished two to three weeks prior to the experimental procedures.

Casts of the teeth, roentgenograms and color photographs were obtained. Then all mandibular teeth on the left side (\#17-24) were extracted for all the monkeys, leaving the left maxillary teeth (\#9-16) without functional antagonists, while all teeth on the right side were left in normal function to serve as controls.

The animals received a routine diet of Purina Monkey Chow* throughout the experimental period and there was no remarkable loss or gain of weight. One animal (female) died of unknown causes 415 days after the extraction of the teeth. The rest of the animals were sacrificed respectively at 23,89, 189 and 561 days following the extraction.

The jaws and teeth were fixed in $10 \%$ formalin, divided in blocks of two teeth, decalcified and embedded in celloidin. Serial buccolingual sections at 8 microns were cut through the blocks and saved in numerical order. Thirty sections from each tooth, 10 sections apart, were stained with hematoxylin and eosin and used to survey for the most suitable area of each tooth to be measured. After the field had been selected, additional sections from that area were stained.

Histometric measurements and cell counts were sampled from teeth $\# 10,12-16$ on the experimental side and \#1-5 and \#7 on the control side. The maxillary central incisors (\#8 and 9), were excluded since the rhesus monkeys chew with some lateral excursions, meaning that function and nonfunction would overlap in this area. The maxillary cuspids (\#6 and 11) also were omitted because of the marked anatomical and functional differences of these teeth in monkeys and humans.

On the basis of a pilot study of numerous sections from a few teeth, it was determined that measurements from five selected central sections of each tooth with at least two-thirds of the length of the root containing pulp tissues, provided representation of acceptable significance of the buccal and palatal periodontal tissues. These five sample sections were selected from equal intervals as far as possible from each other after reviewing all central sections of the teeth which contained

*Ralston Purina Company, St. Louis, Missouri. 


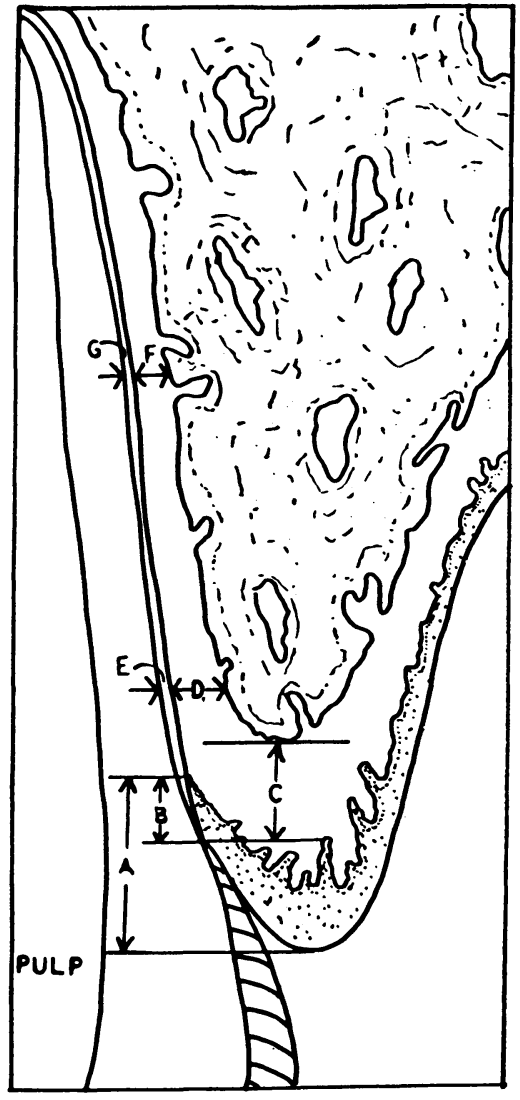

FIGURE 1. Schematic drawing of the sampling sites for the histometric measurements.

pulp in $2 / 3$ or more of the length of the root. The buccal samples of the maxillary molars were all from the mesiobuccal roots.

Seven histometric measurements were obtained from each of the sampled sections as illustrated in Figure 1. All vertical or longitudinal measurements were oriented parallel to the surface of the dentin, and the horizontal measurements were made perpendicular to the dentin surface. The letter designations from " $A$ " to " $G$ " stand for the following distances: " $A$ " for the distance between the free gingival margin and the apical end of the epithelial attachment, " $\mathrm{B}$ " is the distance from the cementoenamel junction to the apical end of the epithelial attachment, " $\mathrm{C}$ " is the distance between the cementum enamel junction and the tip of the alveolar crest. " $D$ " is the width of the periodontal membrane, and " $E$ " the thickness of the cementum-both measurements $0.2745 \mathrm{~mm}$ apically to the alveolar crest. The width of the periodontal membrane $(\mathrm{F})$ and the thickness of the cementum (G) were also measured at the midpoint of the functional root (midpoint of the distance from the alveolar crest to the apex of the root).

A screw micrometer eyepiece,* was calibrated to a

\footnotetext{
*Ernst Leitz Co., 468 Park Avenue, East, New York, New York.
}

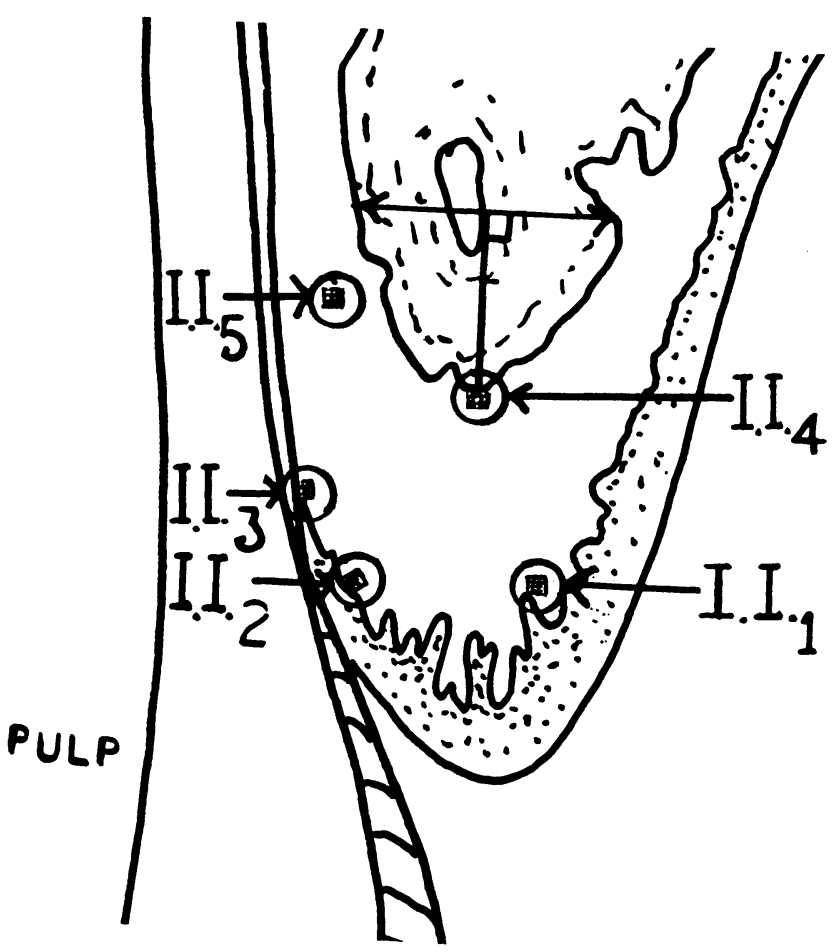

FIGURE 2. Schematic drawing of the sampling sites for the inflammatory indices.

$4 \times$ objective lens at a magnification of $50 \times$. Each of the measurements was recorded from the micrometer eyepiece and converted into millimeters using the calibration factor of one drum interval equal to 0.000915 $\mathrm{mm}$.

The severity of inflammation was assessed in five specifically located areas (Fig. 2) in each of the sampled sections. The locations of these areas (Fig. 2) were: I.I. ${ }_{1}$, under the surface gingival mucosa one-tenth of the thickness of the gingival connective tissues at a distance two-thirds of the length from the gingival margin to the apical end of the epithelial attachment; I.I.2 is immediately subjacent to the crevicular epithelium, at two-thirds of the distance from the free gingival margin to the apical end of the epithelial attachment; I.I. 3 is immediately apically to the apical end of the epithelial attachment; I.I..$_{4}$ is tangential to the alveolar crest at the center of a line bisecting the alveolar process at a distance of $0.549 \mathrm{~mm}$ apically to the most coronal projection of the crest; I.I. 5 is at the middle of the crestal part of the periodontal membrane at a distance of 0.2745 $\mathrm{mm}$ apically to the most coronal projection of the alveolar crest.

The cell counts in these areas were made through a square $10 \times 10$ grid* in the eyepiece, and at a magnification of 1,000 with oil immersion. The focal length

*Bausch and Lomb Optical Company, Rochester, New York. 
was not altered during cell counting for any one field, since it was found in a pilot study that varying the level of focus would alter the cell count. First all cells within the field of the grid were counted except for the intravascular cells. Then all inflammatory cells within the same field were counted. No attempt was made to differentiate type of inflammatory cells. An inflammatory index (I.I.) for each of the sampled areas was computed by dividing the number of inflammatory cells by the total number of cells and multiply by 100 . A mean inflammatory index (I.I. $\bar{x}$ ) was also calculated from the five sample indices.

A total of 521 sections from the five animals were selected on the basis of the described criteria and subjected to all listed measurements and cell counts. Thus there were four variables (functional status, time, tooth number and buccal or lingual surfaces) for any single measurement or inflammatory index.

The means and standard deviations were calculated for each of the measurements and inflammatory indices. Correlation coefficients between each of the measurements were also calculated, but for these correlation coefficients the measurements were not classified according to experimental variables (functional status, time, tooth number and surface).

The means, standard deviation, and standard error of the means were calculated with respect to three of the four experimental variables (functional status, time, and surface) for all measurements except the width of the periodontal membrane and cementum thickness just apical to the alveolar crest (measurements D and E, Fig. 1). Experimental variation due to tooth number was not considered, since all teeth were either classified as functional or nonfunctional. This method of classification resulted in a large sample size taken from six nonfunctional and six functional teeth in each animal. Analysis of variance was used to test for significance between means in the groups of sections examined.

\section{RESULTS}

The means, standard deviations, and sample size (number of sections) are presented in Table 1. The large standard deviation in some of the measurements is expected since for this portion of the analysis, the measurements were not classified with respect to the experimental variables of functional status, time, tooth number or tooth surface.

Table 2 presents selected findings of the correlation coefficients between pairs of measurements and indices of inflammation.

The means and results of analysis of variance with respect to functional status and surface (buccal or
TABLE 1

Means and Standard Deviations for the Linear Measurements (A-G), Figure 1, and the Indices of Inflammation (I.I.), Figure 2, Without Respect to Experimental Variables

\begin{tabular}{cccc}
\hline Measurements & Mean $(\mathrm{mm})$ & $\begin{array}{c}\text { Standard } \\
\text { Deviation }\end{array}$ & $\begin{array}{c}\text { Number of } \\
\text { Sections }\end{array}$ \\
\hline $\mathrm{A}$ & 1.404211 & .497846 & 507 \\
$\mathrm{~B}$ & 1.066639 & .792241 & 514 \\
$\mathrm{C}$ & 1.645399 & .844769 & 518 \\
$\mathrm{D}$ & .159708 & .110743 & 517 \\
$\mathrm{E}$ & .102973 & .049438 & 509 \\
$\mathrm{~F}$ & .099039 & .050992 & 488 \\
$\mathrm{G}$ & .156434 & .102047 & 473 \\
\hline Index of & & Standard & Number of \\
Inflammation & Mean & Deviation & Sections \\
\hline I.I.1 & 14.4 & 18.2 & 507 \\
I.I.2 & 49.5 & 23.0 & 509 \\
I.I.3 & 15.7 & 16.3 & 510 \\
I.I.4 & 1.6 & 3.2 & 513 \\
I.I.5 & 6.2 & 10.8 & 518 \\
I.I. & 17.4 & 8.6 & 501 \\
\hline
\end{tabular}

TABLE 2

Correlation Coefficients Between Selected Measurements and Indices of Inflammation (I.I.) Without Respect to Experimental Variables

\begin{tabular}{cccl}
\hline $\begin{array}{c}\text { Measurement } \\
\text { Pairs }\end{array}$ & $\begin{array}{c}\text { Number of } \\
\text { Sections }\end{array}$ & $\begin{array}{c}\text { Correlation } \\
\text { Coefficients }\end{array}$ & Significance \\
\hline I.I.5-D & 517 & 0.333 & $\mathrm{p}<.0005$ \\
G-F & 472 & 0.111 & $\mathrm{p}<.01$ \\
D-E & 509 & -0.013 & $\mathrm{p}>.05$ \\
I.I.5-E & 509 & -0.087 & $\mathrm{p}<.025$ \\
B-C & 514 & 0.815 & $\mathrm{p}<.0005$ \\
A-C & 507 & 0.267 & $\mathrm{p}<.0005$ \\
I.I.4-C & 513 & 0.070 & $\mathrm{p}>.05$ \\
I.I.-C & 501 & 0.225 & $\mathrm{p}<.0005$ \\
I.I.2-B & 509 & 0.116 & $\mathrm{p}<.005$ \\
I.I.3-B & 509 & 0.146 & $\mathrm{p}<.005$ \\
I.I.-B $-B$ & 501 & 0.247 & $\mathrm{p}<.0005$ \\
\hline
\end{tabular}

palatal) are presented in Table 3 for the linear measurements and Table 4 for the indices of inflammation.

\section{Periodontal Membrane}

The mean width of the periodontal membrane at the mid-point of the root (F) was less in nonfunctional than functional teeth (Table 3). Although the differences were greater for the palatal than for the buccal measurements, both differences were statistically significant $(\mathrm{p}<.01)$.

Experimental time did not have any consistent effect on the mean width of the periodontal membrane of functional teeth, but teeth without functional antagonists for 89 to 561 days had a mean width of the periodontal membrane approximately one-half to two-thirds that of teeth without function for 23 days. 
Table 3

Means in mm. and Analysis of Variance with Respect to

Functional Status and Surface for Linear Measurements (See Fig. 1)

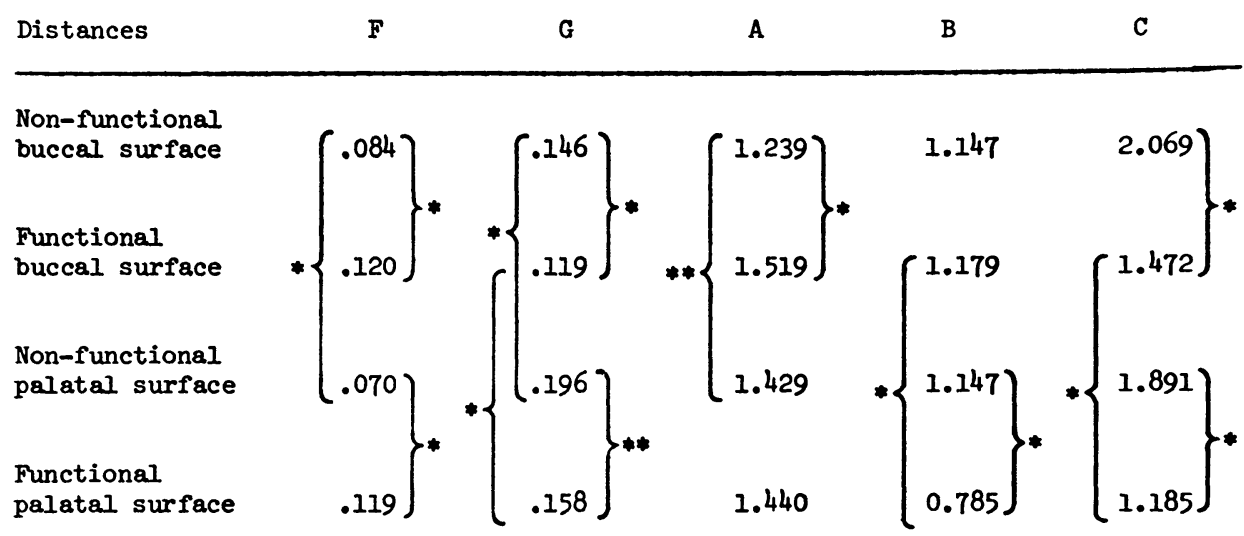

Difference between these means is statistically significant at $\mathrm{P}<.01$.

Difference between these means is statistically significant at $\mathrm{P}<.05$.

Table 4

Means and Analysis of Variance with Respect to Functional

Status and Surface for Indices of Inflammation (See Fig. 2).

\begin{tabular}{|c|c|c|c|c|c|c|}
\hline $\begin{array}{l}\text { Inflammatory } \\
\text { Indices }\end{array}$ & $(I \cdot I \cdot 1)$ & $\left(I \cdot I \cdot{ }_{2}\right)$ & $(I \cdot I \cdot 3)$ & $\left(I . I \cdot{ }_{4}\right)$ & $\left(I . I \cdot{ }_{5}\right)$ & $(I \cdot I \cdot \bar{x})$ \\
\hline $\begin{array}{l}\text { Non-functional } \\
\text { buccal surface }\end{array}$ & $(25.6)$ & 55.7 & $21.7)$ & 1.8 & 5.4 & 22.1 \\
\hline $\begin{array}{l}\text { Functional } \\
\text { buccal surface }\end{array}$ & 15.5 & 53.4 & $\{12.9\}$ & 1.7 & $\int 7.6$ & $18.0 \mathrm{~J}$ \\
\hline $\begin{array}{l}\text { Non-functional } \\
\text { palatal surface }\end{array}$ & 11.9 & 45.5 & 17.6 & 1.9 & * $\{7.9\}$ & $(16.6)$ \\
\hline $\begin{array}{l}\text { Functional } \\
\text { palatal surface }\end{array}$ & 5.8 & 45.4 & 10.8 & 1.0 & $3.7)$ & $13.4 J$ \\
\hline
\end{tabular}

Difference between these means is statistically significant

at $\mathrm{P}<.01$.

Difference between these means is statistically significant

at $\mathrm{P}<.05$. 


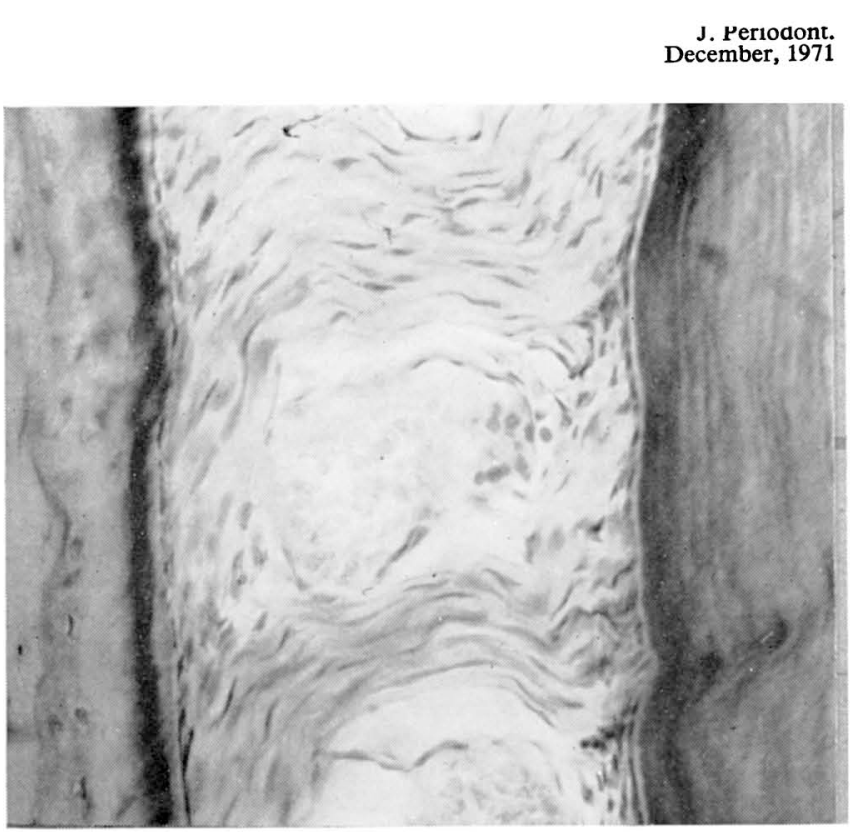

There was no significant difference in the mean inflammatory index in the periodontal membrane just apical to the alveolar crest (I.I.5) between functional and nonfunctional teeth on the buccal surface (Table 4). However, on the palatal surface of nonfunctional teeth, the mean inflammatory index at this location was significantly greater than the corresponding surface of the functional teeth (by 4.2 index units, $\mathrm{p}<.01$, Table 4).

There was no significant difference in the mean inflammatory index in the periodontal membrane just apical to the alveolar crest (I.I.5) between the buccal and palatal surfaces of nonfunctional teeth (Table 4). The mean inflammatory index just apical to the alveolar crest (I.I.5) was, however, significantly greater on the buccal than the palatal surface of functional teeth (by 3.9 index units, $\mathrm{p}<.01$, Table 4 ).

Experimental time did not have any consistent effect on the inflammatory index in the periodontal membrane (I.I. ${ }_{5}$ ) when functional and nonfunctional teeth were considered as a group.

A low positive correlation coefficient (.333, p $<.0005)$ between the index of inflammation in the periodontal membrane (I.I.5) and the width of the periodontal membrane at the same location (measurement D) was found (Table 2).

The periodontal membrane of nonfunctional teeth in animals of longer experimental time periods demonstrated a marked degree of atrophy with total loss of functional orientation of fiber bundles. The connective tissue cells of the periodontal membrane in nonfunctional teeth were also orientated parallel to the long axis of the teeth. The decrease in width of the periodontal membrane as well as the structural alterations are demonstrated in Figures 3 and 4.

\section{Cementum}

The mean thickness at the mid-point of the root (G) was significantly greater in nonfunctional than functional teeth (Table 3 ). The increase was greater when palatal surfaces were compared than when buccal surfaces were compared, but both were statistically significant. The mean thickness of cementum was also significantly greater on the palatal surface when both functional and nonfunctional teeth were compared (Table 3).

Experimental time did not have any consistent effect on the cementum thickness at the mid-point of the root when the functional or nonfunctional teeth were considered as a group.

A very low positive coefficient of correlation (.111, $\mathrm{p}<.01$ ) was found between the cementum thickness

FIGURE 3. Periodontal membrane of functioning tooth (\#2) at the midpoint of the mesiobuccal root from the 561 day animal. Original magnification X365.

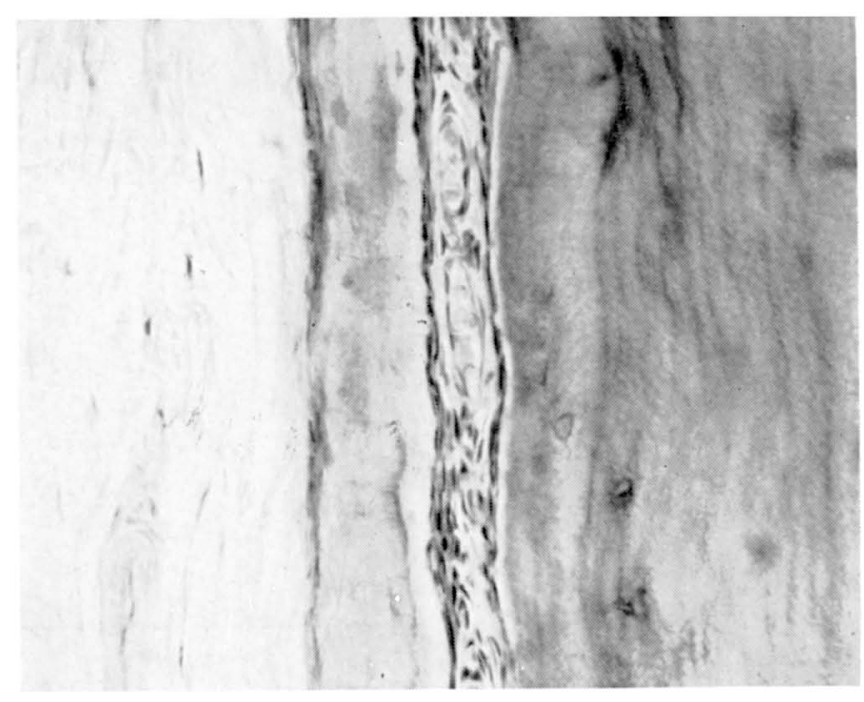

FIgURE 4. Periodontal membrane of nonfunctioning tooth (\#15) at the midpoint of the mesiobuccal root from the 561 day animal. Original magnification same as for Figure 4 (X365).

(G) at the mid-point of the root and the width of the periodontal membrane $(\mathrm{F})$ at the same location (Table $2)$. There was no significant correlation between the cementum thickness just apical to the alveolar crest (E) and the width of the periodontal membrane (D) at the same location. The index of inflammation in the periodontal membrane just apical to the alveolar crest (I.I.5) and the cementum thickness (E) at this location had a very low negative coefficient of correlation $(-.087$, $\mathrm{p}<.025$, Table 2).

\section{Bone}

The position of the alveolar crest, as measured from the cementoenamel junction ( $C$, Table 3 ) was located 
significantly more apically on nonfunctional than functional teeth. The difference was greater when palatal surfaces were compared $(.706 \mathrm{~mm})$ than when buccal surfaces were compared $(.597 \mathrm{~mm})$, but both were statistically significant.

The alveolar crest of functional teeth was located more apically on the buccal surface than on the palatal surface. On the nonfunctional teeth, there was no significant difference in the mean distance from the cementoenamel junction to the alveolar crest when surfaces were compared (Table 3 ).

Experimental time did not have any consistent effect on the mean height of the alveolar crest relative to the cementoenamel junction.

A very high positive correlation coefficient (.815, $\mathrm{p}<.0005$ ) was found between the distance from the cementoenamel junction to the most apical location of the epithelial attachment (B) and the distance from the cementoenamel junction to the alveolar crest $(\mathrm{C}$, Table 2). The distance from the cementoenamel junction to the alveolar crest (C) was correlated in a rather low degree $(.267, \mathrm{p}<.0005$, Table 2$)$ with the distance from the free gingival margin to the most apical location of the epithelial attachment (A).

The height of the alveolar crest relative to the cementoenamel junction (C) was not significantly correlated to the index of inflammation at the alveolar crest (I.I.4, Table 2). A low positive correlation coefficient $(.225, \mathrm{p}<.0005$, Table 2$)$ was found between the distance from the cementoenamel junction to the alveolar crest $(\mathrm{C})$ and the mean index of inflammation (I.I. $\cdot \bar{x}$, Table 2).

The mean inflammatory index at the alveolar crest (I.I. ${ }_{4}$ ) was not significantly different between functional and nonfunctional teeth when buccal and palatal surfaces were compared. There was no significant difference in the inflammatory indices at the alveolar crest (I.I.4) between surfaces of functional or nonfunctional teeth (Table 4).

\section{Gingiva}

The mean distance from the free gingival margin to the most apical location of the epithelial attachment (A) was significantly greater $(.280 \mathrm{~mm}, \mathrm{p}<.01)$ on functional than nonfunctional teeth when the buccal surfaces were compared (Table 3 ). On the palatal surfaces however, there was no significant difference in this measurement between functional and nonfunctional teeth.

The mean distance from the free gingival margin to the most apical location of the epithelial attachment (A) was greater $(.190 \mathrm{~mm}, \mathrm{p}<.05)$ on the palatal than the buccal surface on nonfunctional teeth (Table 3 ). No significant difference was found between surfaces on the functional teeth with respect to this measurement.

The mean distance from the cementoenamel junction to the most apical location of the epithelial attachment (B) was significantly greater on nonfunctional than functional teeth $(.362 \mathrm{~mm}, \mathrm{p}<.01$, Table 3$)$ when palatal surfaces were compared. No significant difference in this measurement was found between functional and nonfunctional teeth when the buccal surfaces were compared (Table 3 ).

The mean distance from the cementoenamel junction to the most apical location of the epithelial attachment (B) was significantly greater $(.394 \mathrm{~mm}, \mathrm{p}<.01$, Table 3 ) on the buccal than the palatal surface of functional teeth. No significant difference between means of this measurement on the buccal and palatal surfaces of the nonfunctional teeth was found (Table 3 ).

Fairly low coefficients of correlation were observed between the distance from the cementoenamel junction to the most apical location of the epithelial attachment (B) and the indices of inflammation from various locations (I.I. , I.I. $_{3}$ and I.I.. $\bar{x}$, Table 2).

The mean inflammatory indices from location I.I. $_{1}$ and I.I. $_{.3}$ (See Fig. 1) in the gingiva of the nonfunctional teeth were significantly greater than the indices from the gingiva of functional teeth at both for buccal and palatal surfaces (Table 4).

The mean index of inflammation under the oral surface of the gingiva I.I.1 was significantly greater on the buccal than the palatal surfaces of both functional and nonfunctional teeth (Table 4).

There was no significant difference in the mean inflammatory indices from the locations just apical to the epithelial attachment (I.I.3) between buccal and palatal surfaces of functional teeth, but the mean index of inflammation from this location was significantly greater on the buccal than the palatal surface of nonfunctional teeth (Table 4).

The inflammatory indices from the gingiva (I.I. ${ }_{1}$ and I.I. ${ }_{3}$ ) of the 561 day animal were greater than for the four other animals both when functional and nonfunctional teeth were considered.

The inflammatory indices adjacent to the epithelial attachment (I.I..$_{2}$ ) were not significantly different for functional and nonfunctional teeth either when buccal or palatal surfaces were compared (Table 4). The inflammatory indices at this location were however significantly greater on the buccal than the palatal surface of both functional and nonfunctional teeth (Table 4). 
The mean of all inflammatory indices (I.I. $\cdot \bar{x}$ ) was significantly greater for the periodontal tissue of nonfunctional than functional teeth. Although the mean difference in the inflammatory indices was greater when buccal surfaces were compared than when palatal surfaces were compared, both were statistically significant (Table 4). The mean inflammatory index was also greater on the buccal than the palatal surface of both the functional and the nonfunctional teeth (Table 4). The 561 day animal had a greater mean inflammatory index than the other animals both for the functional and the nonfunctional teeth.

Clinically there appeared to be more plaque, calculus, and gingivitis associated with the nonfunctional teeth than with the functional teeth. The nonfunctional teeth of animals of longer experimental time periods were also hypererupted.

Clinical observation and color photographs showed clearly more plaque, calculus and gingivitis on the nonfunctional than associated with the functional teeth. The nonfunctional teeth in the 415 and 561 day animals were noticeably hypererupted compared with the functional side.

\section{SignificANCE}

\section{Periodontal Membrane}

The narrowing of the periodontal membrane both buccally and palatally with decreased function reported in this study agrees with previous observation in humans ${ }^{1-14}$ and animals. ${ }^{15-20}$ The width of the periodontal membrane at the midpoint of teeth without antagonists for three to six months was about one-half to two-thirds of the width of the periodontal membrane of the threeweek experimental teeth. After three months of nonfunction, no consistent decrease in width was observed, which indicated that the narrowing of the periodontal membrane primarily occurred during the first three months of nonfunction.

The spread of gingival inflammation into the cervical aspect of the periodontal membrane apparently was not affected by the functional status on the buccal side. However, on the palatal side there was significantly more inflammatory cells entering the periodontal membrane of the nonfunctioning than of the functioning teeth. Previous investigators ${ }^{20}$ have found no such difference between functioning and nonfunctioning teeth, but they did not examine buccolingual sections and did not evaluate inflammation mathematically so their findings are not directly comparable with the present study.

Cleaning effect of mastication in monkeys may effect plaque retention more on the palatal than on the buccal aspect of the teeth since on the functioning teeth there was less inflammation penetrating to the periodontal membrane on the palatal than on the buccal side while on the nonfunctioning side there was no such difference.

The observed atrophic changes and loss of functional orientation of the periodontal fiber bundles of nonfunctional teeth confirmed previous reports concerning humans $^{1-14}$ and animals. ${ }^{15-20}$

\section{Cementum}

The increased thickness of the cementum at the midpoint of the roots of nonfunctional compared with functional teeth agrees with previous reports from studies in humans ${ }^{5,8,9,12,21}$ and monkeys. ${ }^{20,22}$

There did not appear to be a strong correlation between the width of the periodontal membrane and the thickness of the cementum in the measured areas when all teeth were included. However, in nonfunctioning teeth the width of the periodontal membrane decreased with increase in thickness of the cementum, but the increased thickness of cementum accounted only for a small part of the decrease in width of the periodontal membrane.

\section{Bone}

As previously reported in humans, ${ }^{13}$ macaca cyanomolgus monkeys, ${ }^{20}$ and rodents, ${ }^{25,}{ }^{26}$ there was in the present study histologic evidence of crestal apposition of bone adjacent to the nonfunctional teeth. The nonfunctional teeth, especially in the two longest experimental terms, were noticeably hypererupted. However, neither the amount of new bone formation nor the distance of hypereruption could be measured with acceptable accuracy from the present material.

Since the distance from the alveolar crest to the cementoenamel junction was significantly greater for the nonfunctional than for the functional teeth, it appears that the crestal apposition of bone did not occur as fast as the rate of hypereruption. A net loss of alveolar support thus resulted for the nonfunctional teeth. It is also possible that the increased severity of inflammation around the nonfunctional teeth had interfered with the formation of new bone at the crest and thus contributed to the increased distance between the alveolar crest and the cementoenamel junction of these teeth. The very high positive correlation between the distance from the cementoenamel junction to the apical end of the epithelial attachment, and the distance from the cementoenamel junction to the alveolar crest could be taken to indicate that inflammation had lead to increased downgrowth of the epithelial attachment of the nonfunctional teeth and thus also influenced the lowering of the bone level. However, when the relationships between the locations of the epithelial at- 
tachments and the crests for the buccal and palatal aspects of the functioning and nonfunctioning teeth were compared it appears that the different levels of crestal bone between the functional and nonfunctional side must be due to some factors other than the severity of their periodontitis.

The height of the alveolar crest relative to the cementoenamel junction was not correlated with the inflammatory index at the alveolar crest (I.I.4, Fig. 2).

However, there was a low but significant correlation between the mean of all inflammatory indices (I.I. $\cdot$, Fig. 2) and the distance from the alveolar crest to the cementoenamel junction.

Crestal bone resorption in the absence of periodontal inflammation as reported for rats, ${ }^{15,17}$ was never observed in the present study.

The supporting bone of the nonfunctional teeth, especially from the longer experimental periods, showed increased size of marrow spaces and thinner trebeculi than on the functioning side as reported previously. ${ }^{1,2,5}$, $8,11,12,23$

\section{Gingiva}

The lesser distance from the free gingival margin to the apical end of the epithelial attachment on functional than nonfunctional teeth on the buccal side was probably related to the hypererupting teeth "outgrowing" part of the pockets, since there was no difference between the distances from the cementoenamel junction to the apical end of the epithelial attachment of these teeth.

The greatest severity of inflammation was observed at the buccal surfaces of the nonfunctional teeth, followed respectively by the buccal surfaces of functional teeth, the palatal surfaces of nonfunctional teeth, and the palatal surfaces of functional teeth. Since plaque and calculus were not measured in the present study, it can be stated only as a definite observation that the nonfunctional teeth had a greater accumulation of plaque and calculus than the functional teeth, which probably accounted for the differences in gingival inflammatory indices between the two sides.

\section{SUMMARY}

The left mandibular teeth to the midline were extracted in five adult rhesus monkeys. The monkeys were sacrificed after respectively 23, 89, 189, 415 and 561 days. Decidedly more plaque and calculus accumulated on the nonfunctional left maxillary teeth than on the functional right maxillary teeth.
Histometric measurements and computed inflammatory indices from selected areas were compared.

It was found that:

1. The gingival inflammatory index was significantly higher for nonfunctional than for functional teeth.

2. The distance from the cementoenamel junction to the alveolar crest was significantly greater in nonfunctional compared to functional teeth.

3 . The distance from the cementoenamel junction to the apical end of the epithelial attachment was related directly to the distance from the cementoenamel junction to the alveolar crest.

4. The periodontal membrane was narrower and the cementum thicker for nonfunctional than for functional teeth.

\section{CONCLUSIONS}

For the rhesus monkeys it is concluded that:

1. Nonfunction increases gingival inflammation.

2. Nonfunction leads to an increased loss of bony support for the teeth compared with functional teeth.

3. The distances from the cementoenamel junction to the apical end of the epithelial attachment and the distances from the cementoenamel junction to the alveolar crest are highly correlated.

4. Nonfunction leads to a narrowing of the periodontal membrane.

5. The cementum increases faster in thickness on nonfunctional than on functional teeth.

\section{ACKNOWLeDgments}

The histologic sections were prepared by Jean I. Simons and Virginia W. Hartog at the Veterans Administration Hospital, Ann Arbor, Michigan.

\section{REFERENCES}

1. Bodecker, C.: Critical review of Gottlieb and Orban's "Die Veränderungen der Gewebe Bei Ubermässiger Beanspruchung der Zähne," Int. J. Ortho., Oral Sur., and Radiogr., 18:895-917, 1932.

2. Box, H. K.: The Pericementum as Influenced by Physical Functional Modifications. Int. J. Ortho., Oral Surg., and Radiogr., 19:574-583, 1933.

3. Coolidge, E. D.: The Thickness of the Human Periodontal Membrane. J. Amer. Dent. Assoc., 24:1260-1270, 1937.

4. Frölich, E.: The Structure of the Periodontal Membrane in Relation to the Direction of Intensity of its Function. Deutsch. Zahnaerztl. Z., 22:798-806, 1967.

5. Gottlieb, B. and Orban, B.: Biology and Pathology of the Tooth and its Supporting Mechanism. Translated and edited by Moses Diamond. New York, MacMillan Co., 1938. 
6. Henry, J. L. and Weinmann, J. P.: The Pattern of Resorption and Repair of Human Cementum. J. Amer. Dent. Assoc., 42:270-290, 1951.

7. Jozat, R.: Über Veränderungen des Periodontiums durch Entlastung. Deutsch. Zahnaerztl. W., 36:155, 1933.

8. Kellner, E.: Histologische Befunde an Antagonistenlosen Zähnen. Ztschr. f. Stomatol., 26:271-283, 1928.

9. Kellner, E.: Das Verhaltnis der Zement-und Periodontalbreiten zur Funktionellen Beanspruchung der Zähne. Ztschr. f. Stomatol., 29:44-62, 1931.

10. Klein, A.: Systematische Untersuchungen uber die Periodontal Breite. Ztschr. f. Stomatol., 26:417-439, 1928.

11. Kronfeld, R.: Histologic Study of the Influence of Function on the Human Periodontal Membrane. J. Amer. Dent. Assoc., 18:1242-1274, 1931.

12. Kronfeld, R.: Histopathology of the Teeth and Their Surrounding Structures, 3 ed. Philadelphia, Lea and Febiger, edited by Boyle, P. E., 1949.

13. Ramfjord, S. P. and Kohler, C. A.: Periodontal Reaction to Functional Occlusal Stress. J. Periodont., 30:95$112,1959$.

14. Weinmann, J. P.: The Adaptation of the Periodontal Membrane to Physiologic and Pathologic Changes. Oral Surg., Oral Med., Oral Path., 8:977-981, 1955.

15. Cohn, S. A.: Disuse Atrophy of the Periodontium in Mice. Arch. Oral Biol., 10:909-919, 1965.

16. Eccles, J. D.: The Effects of Reducing Function and Stopping Eruption on the Periodontium of the Rat Incisor. J. Dent. Res., 44:860-868, 1965.

17. Horowitz, S. L. and Shapiro, H. H.: Alveolar Bone
Changes Following Alteration in Masticatory Function of the Rat. N.Y.S. Dent. J., 22:212-217, 1956.

18. Krikos, G., Beltran, R., and Cohen, A.: Significance of Mechanical Stress on the Development of Periodontal Lesions in Lathyritic Rats. J. Dent. Res., 44:600-607, 1965.

19. Presisecker, O.: Beeinflussing des Periodontiums durch Experimentelle Entlastung. Ztsch. f. Stomatol., 29: 442-446, 1931.

20. Anneroth, G. and Ericsson, S. G.: An Experimental Histological Study of Monkey Teeth Without Antagonist. Odont. Revy., 4:345-359, 1967.

21. Kronfeld, R.: The Biology of Cementum. J. Amer. Dent. Assoc., 25:1451-1461, 1938.

22. Ericsson, S. G.: Quantitative Microradiography of Cementum and Abraded Dentin. Acta. Radiolog. Stockholm. Suppl. 246, 1965.

23. Orban's B.: Dental Histology and Embryology. 2 ed. Blakiston Sons and Co., Philadelphia, 1929.

24. Anderson, B. G., Smith, A. H., Arnim, S. S. and Orten, A.: Changes in Molar Teeth and Their Supporting Structures of Rats Following Extraction of the Upper Right First and Second Molars. Yale J. Biol. Med., 9:189-195, 1936.

25. Glickman, I.: The Effect of Acute Starvation upon the Apposition of Alveolar Bone Associated with the Extraction of Functional Antagonists. J. Dent. Res., 24:155$160,1945$.

26. Basu, M.: Changes in the Periodontium of Teeth Without Antagonists. (abstract), J. Dent. Res., 47:985-986, 1968.

\section{Announcements}

\section{UNIVERSITY OF PENNSYLVANIA}

The University of Pennsylvania announces the following Continuing Education courses:

Dr. D. Walter Cohen and associates will present a five-day Refresher Course for those in Limited Practice of Periodontics January 24th through 28th, 1972. This course for periodontists will review in detail such subjects as tooth movement as part of periodontal therapy, modifications in surgical technics including gingival and osseous grafts, new methods of temporary stabilization and objectives and case planning for periodontal prosthesis.

Drs. D. Walter Cohen and Morton Amsterdam will present a one-day Refresher Course in Periodontal Therapy Saturday, February 19,1972 . This seminar will review current advancements in periodontal therapy for those who have had basic postgraduate instruction in periodontics.

Drs. Morton Amsterdam, D. Walter Cohen and associates will present a five-day course on Periodontal Prosthesis February 21st through 25th, 1972. This course is designed to correlate advanced restorative procedures and periodontal therapeutics in the treatment of pathologic conditions of the teeth and their supporting structures.

Drs. Manual H. Marks, Herman Corn and I. Stephen Brown will present a one-day Refresher Course: Adult Tooth Movement in Comprehensive Dentistry on March 15, 1972. This seminar is designed for those who have taken the course in Adult Tooth Movement in Comprehensive Dentistry or the equivalent, or for those who have had experience in adult tooth movement. Emphasis will be placed on the management of the more difficult adult tooth movement cases.

Dr. Jerome S. Mittelman will present a one-day course on Getting Prevention Through to Your Patients on Wednesday, March 1, 1972. This course will discuss upgrading dental practice by using new practical motivation technics. The discussion will show how a new patient is introduced into the preventive practice step by step and will also detail ways of getting former patients to accept the preventive program.

For further information please write: Continuation CoursesUniversity of Pennsylvania, School of Dental Medicine, 4001 Spruce Street, Philadelphia, Pennsylvania 19104.

\section{UNIVERSITY OF LOUISVILLE SCHOOL OF DENTISTRY}

The University of Louisville, Health Sciences Center, Preston and Walnut Streets, Louisville, Kentucky, announces the following course:

Periodontics 1972, a one-day continuing education course. Dr. A. Gargiulo, Loyola University, March 16, 1972. 